\title{
BMJ Six months fixed duration multidrug Open therapy in paucibacillary leprosy: risk of relapse and disability in Agra PB cohort study
}

\author{
Anil Kumar, ${ }^{1}$ Anita Girdhar, ${ }^{2}$ Bhavneswar Kumar Girdhar ${ }^{2}$
}

To cite: Kumar A, Girdhar A, Girdhar BK. Six months fixed duration multidrug therapy in paucibacillary leprosy: risk of relapse and disability in Agra PB cohort study. BMJ Open 2012;0:e001403.

doi:10.1136/bmjopen-2012001403

- Prepublication history and additional material for this paper are available online. To view these files please visit the journal online (http://dx. doi.org/10.1136/bmjopen2012-001403).

Received 1 May 2012 Accepted 20 July 2012

This final article is available for use under the terms of the Creative Commons Attribution Non-Commercial 2.0 Licence; see http://bmjopen.bmj.com

${ }^{1}$ Department of Biostatistics and Epidemiology, National JALMA Institute for Leprosy, Agra, Uttar Pradesh, India ${ }^{2}$ Department of Clinical, National JALMA Institute for Leprosy, Agra, Uttar Pradesh, India

Correspondence to Dr Anil Kumar; dranil250158@gmail.com

\section{ABSTRACT}

Background: Many studies have focused on multidrug therapy (MDT) for multibacillary (MB) leprosy and rarely on long-term outcome of paucibacillary (PB) leprosy having recommendation of therapy for 6 months fixed duration therapy for PB patients. Studies on measuring risk of disability are rare. The present study is to assess the cure; default, relapse and disability in a prospective cohort of PB leprosy during follow-up of $>4$ years after treatment.

Design: Prospective.

Setting: Primary in our field area of Agra District.

Participants: 920 PB leprosy patients entered the study, 621 completed treatment, 599 followed finally including 271 males, no ethnic differentiation, patients of all age groups except for children below 5 years and old persons above 70 years were not included.

Treatment: 6 months fixed duration MDT as recommended by WHO.

Primary and secondary outcomes: Treatment completion, cure, relapse and development of disability based on clinical assessment by well-experienced doctors.

Statistical methods: Data have been analysed using SPSS software, risk is computed as incidence per 100 person-years (PY) and test of significance used.

Results: Study reports $91 \%$ cure rate. Incidence of relapse was 1.3/100 PY with no significant variation by age, sex, delay in detection, patches and nerves. Crude incidence of disability was $2.2 \%$ and varied significantly by age and nerve thickening but not by sex, number of patches, nerves and delay in treatment. Incidence of disability was $0.50 / 100 \mathrm{PY}$ in treatment completed and 0.43 among defaulters.

Conclusion: The study concludes that relapses do occur after MDT treatment but at the level of $1-2 \%$, incidence of disability remains low ( $<1 / 100$ PY) in PB leprosy. Low incidence of relapse and disability suggests that 6 months therapy is quite effective. However, further improvement may help to improve its efficacy. Longer follow-up may add to efficacy measures.

\section{INTRODUCTION}

Leprosy is unique in terms of the nature of the causative organism, the chronicity of the

\section{ARTICLE SUMMARY}

\section{Article focus}

- How many patients get cured with multidrug therapy (MDT), how many relapse over the years and develop reactions and factors associated?

- What is the incidence of disability among paucibacillary leprosy patients, patients with complete treated versus defaulters?

- Do early defaulters have high disability than late defaulters?

\section{Key messages}

- This study clearly demonstrates that over $90 \%$ patients completely cure with the use of MDT, very few reactions observed but relapses do occur (1.3/100 person-years (PY)) without significant variation.

- It also reveals that the incidence of disability is observed as 0.50/100 PY among treatment completers and does not significantly differ among defaulters even in early defaulters.

- This implies that even a few months' of treatment could be as good as completing treatment as far as developing of disability is concerned but treatment must be started.

Strength and limitations of this study

- The strength of the study is that it is based on a closely followed-up prospective cohort for good length of time and patients were clinically assessed and monitored. However, no limitation could be seen to influence the results.

- One of the limitations of the study design is that not all patients could be submitted to skin smear due to their non-cooperation and histopathology was not planned and thus only clinical classification based on long experience of leprologists in the study was used.

disease, its prolonged treatment and the definitions of cure and relapse. The principal mode of assessing the effectiveness of therapeutic regimens in leprosy is the relapse rate. ${ }^{1}$ The important predisposing factors for relapse include the presence of persister 
bacilli, monotherapy, inadequate or irregular therapy, presence of multiple skin lesions and/or thickened nerves and lepromin negativity. The conventional methods of confirming activity or relapse in an infectious disease have limited utility in leprosy because of the difficulty in demonstrating bacilli in paucibacillary $(\mathrm{PB})$ cases and absence of a method of in vitro cultivation of Mycobacterium leprae. Bacteriological parameters are useful in smear positive multibacillary (MB) leprosy, whereas in PB leprosy the criteria for relapse depend primarily on clinical features since even histological examination cannot clearly distinguish between reaction and relapse. ${ }^{2}$

There are wide variations in estimates of relapse rates in different regions. The risk of relapse from programmebased data was reported ${ }^{2-4}$ to be low from $0.29 \%$ to $1.1 \%$ and in closely monitored studies it was estimated as 1$6.9 \%$ for PB leprosy patients after stopping multidrug therapy (MDT). ${ }^{5}$ Although most of these studies provided crude estimates of relapse, a few also estimated using person-years (PY) of observation, giving relapse rates of $0.65-3.0$ per $100 \mathrm{PY}$ for PB leprosy. ${ }^{5} 78$

One of the reasons for low relapse rate was that follow-up was done usually for shorter intervals after therapy. Besides relapses in PB leprosy, there is hardly any study in the literature reporting the risk of developing disability but one ${ }^{6}$ based on pre-MDT era reported that $6.7 \%$ developed Grade 1 and another 5.2\% Grade 2 disability. However, one recent study based on MDT had given estimates of risk of developing disability of 2.74/100 PY in MB leprosy. ${ }^{9}$ Therefore, more studies on long-tern follow-up were required to assess the risk of relapse and disability rate in the cohort of patients treated with 6 months fixed duration therapy and thus the present study was undertaken in cohort PB leprosy patients from field surveys in Agra District-namely Agra cohort, with the objectives to assess the risk of relapse and disability rate besides the extent of treatment completion and cure rate.

\section{DESIGN AND METHODS}

\section{Study site, field setting and duration of study}

The study was started in our field area in Agra District of Uttar Pradesh on patients detected in field surveys under several studies on the prevalence of leprosy during 20012006. ${ }^{10-13}$ The Agra District is located $200 \mathrm{~km}$ away from Delhi and extends to a radius of $100 \mathrm{~km}$ on either side in length and borders with district Itawa and Firozabad on the eastern side, Mathura and Bharatpur on the north-west side and Gwalior and Dholpur on the southern side. Several studies were undertaken since the district was highly endemic for leprosy with a prevalence of 16.4/ 10000 during 2001-2003 and 7/10 000 during 2004-2006. The present study is based on patients detected in such surveys and all patients were followed up till April 2011.

\section{Inclusion/exclusion criterion of patients for the study}

The study has been conducted in patients detected in the field survey in Agra District during 2001-2006.
Newly detected leprosy patients diagnosed clinically as PB leprosy were included in the study. This included patients with up to five skin lesions, either erythmatous or hypo-pigmented with definite impairment or loss of sensation (tested with ball point pen) and/or one thickened nerves. None of the patients had taken leprosy treatment earlier. Children below 5 years of age and adults above 70 years of age were, however, treated as per the norms but, like pregnant and lactating women, were not included in the study

\section{Cohort size and treatment allocation}

During 2001-2006 in Agra District, several field surveys were undertaken to detect leprosy cases. In these surveys, a total of 1050 PB leprosy cases were detected. After excluding cases given rifampicin, ofloxacin and minocycline (ROM) in the randomised trial, the rest were put on WHO MDT as the cases were detected in ongoing surveys. Of the $920 \mathrm{~PB}$ cases, 48 did not start the treatment (2 due to pregnancy, 2 old-aged, 44 simply refused). After this, of the 872 cases on PB-MDT, $251(28.8 \%)$ discontinued (defaulted) treatments at various durations and due to various reasons. Therefore, a cohort of $599(96.5 \%)$, out of 621 PB patients, completed treatment and could be followed up for a mean duration of 4.39 (SD 1.6) years after completion of MDT treatment. The present study is based on this cohort of 599 cases (see the flow chart).

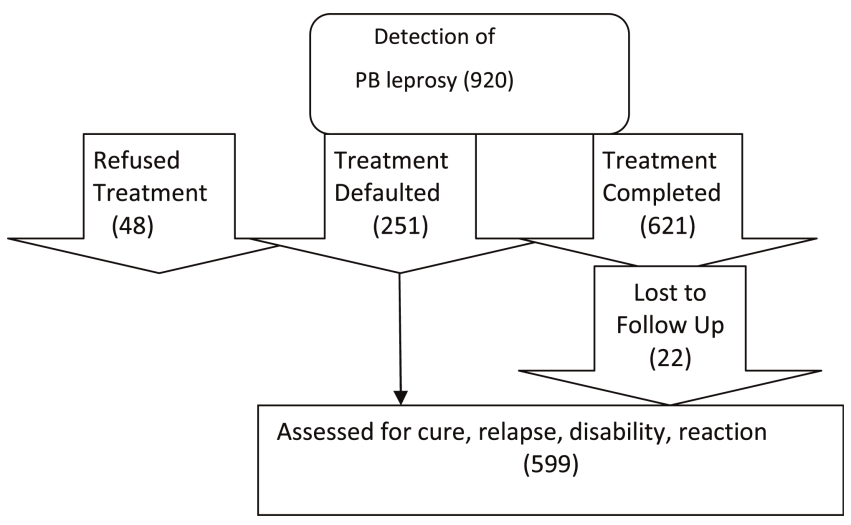

At the start of treatment, all patients were informed about the disease, its implications, treatment, possible side effects, remedies and benefits. Although the treatment given followed WHO standard regimen as in routine government leprosy control programme, for reasons of follow-up and others the patients were asked to give their consent and then were put on respective treatments. In the case of children, consent of their parents was taken.

\section{Treatment}

WHO supplied standard $\mathrm{PB} / \mathrm{MDT}$ packs were used for the study and appropriate WHO-recommended doses 
(available in blister packs) were given to children aged 5-14 and adults (aged >14). Monthly PB-MDT was given, with dose under supervision and for the rest of the days patients were guided to take daily treatment doses of Dapsone.

\section{Follow-up and assessment}

Patients were visited every month till the completion of treatment for drug intake, clinical conditions and side effects. However, formal assessment of each available patient was made every 6 months for 5 years and annually thereafter. Lesion activity-erythema, infiltration and size, reaction, any new lesion and/or new nerve thickening or any deformity-was recorded in consultation with the medical doctor who was a part of the study. Cure of the disease was defined as complete healing of the lesion or patch becoming flat hypopigmented with decrease in the size of the lesion and/or regain of sensations. Loss to follow-up was defined when patients could not be assessed for fairly long time.

\section{Defining defaulter}

A patient who did not complete scheduled 6 months MDT to be able to declare cured. An early defaulter is the one who did not have more than 2 months of MDT and a late defaulter is one who had 3-5 months MDT.

\section{Defining relapse or reaction}

The case of relapse was confirmed by a clinician with $>30$ years experience in leprosy. Gradual or insidious appearance of new lesion(s) or definite increase in the size of the lesion and/or appearance of new nerve thickening were taken as relapse. Any sudden redness, swelling of the lesion with or without new lesion especially during the first 6-12 months of follow-up was considered as late reaction. All such patients were first put on corticosteroids. ${ }^{14}$ If there was no obvious change in morphology of lesion (inflammation) in 4 weeks, the patients were considered to have relapsed. If a patient responded to 4 weeks of corticosteroids, then it was recorded as reaction and not relapse.

\section{Defining disability of Grade 1 and Grade 2}

Disability Grade 1 was defined as patient developing anaesthesia in palm or sole tested with a ball point pen and Grade 2 as visible deformity in either hand or feet or eye (Lagophthalmas). During this time, all cases of clinical relapse, reaction and developing of disability (Grade 1 and Grade 2) were recorded after medical confirmation and necessary medical relief was either provided or referred.

\section{Ethical approval and informed consent}

Ethical approval was taken from the Institutional Ethical Committee that was being informed periodically about the progress of the work. All the patients were informed about the possible side effects, remedies and benefits. Although the treatment given followed WHO standard regimen, for reasons of follow-up and others, the patients were asked for their consent and then were put on respective treatment. In the case of children, consent of their parents was taken.

\section{Statistical methods}

The comparison of patients developing disability was done using survival analysis and log-rank test to check the significance ${ }^{15}$ using SPSS V.12 software and Fisher's exact test or $\chi^{2}$ test of significance was used to compare proportions.

\section{RESULTS}

\section{Demographic characteristics of patients}

The patients of all ages were detected in surveys. The mean age was 34.2 years $(\mathrm{SEM}=0.6)$. About half of the total patients $(49.7 \%)$ were aged 35 and above and only $12.5 \%$ were children ( $<15$ years). Male patients in this study accounted for $45.3 \%$ of the total 872 cases put on PB-MDT. At the time of survey, $51.8 \%$ patients were those who reported to acquire leprosy during the last 12 months, $32.3 \%$ in the last $12-36$ months and the rest had disease since over 36 months. A total of $79.1 \%$ had up to two skin patches, $40.3 \%$ with one thickened nerve, $84.6 \%$ with borderline tuberculoid (BT) disease and only $0.3 \%$ (two cases) were smear positive, that too just $1+$. Similar distribution is observed among those who completed treatment and defaulters (table 1).

About $40 \%$ of the patients had one thickened nerve (main trunk or the cutaneous one) as observed in this study. The main nerve involved was ulnar $(64.2 \%)$, ulnar cutaneous $(4.6 \%)$, lateral popliteal $(24 \%)$, radial $(0.9 \%)$, radial cutaneous $(3.2 \%)$ and rest others $(3.2 \%)$. About 2.5\% had neuritic leprosy (no skin lesions).

\section{Treatment completion, cure rate and reaction}

Of the total 872 patients who were put on PB-MDT treatment, 621(71.2\%) completed their standard 6 months treatment and 251 (28.8\%) defaulted at various stages of treatment. Among the defaulters, $70.1 \%$ defaulted early (within 3 months) and $29.9 \%$ during $3-5$ months treatment.

Among 621 completed treatments, only 599 could be followed up and 22 were lost to follow-up. About $83 \%$ of the patients could be followed up for 3-8 years and some $2.9 \%$ for over 8 years. A total of $545(91 \%)$ of the 599 were observed to be completely cured, $1.7 \%$ either not cured or partially cured and the rest were observed to have either relapsed (35), developed reaction (5/599) or developed disability of Grade 1 (5) or Grade 2 (8) (table 2).

\section{Incidence of relapse}

The overall incidence of relapse was observed to be 1.3 per $100 \mathrm{PY}$ (figure 1). The incidence of relapse by age, although, did not change much, but was observed to be slightly high in children $(<15$ years $)$ and among older 
Table 1 PB leprosy patients by demographic and clinical status, Agra District (UP) India during 2001-2006

\begin{tabular}{|c|c|c|c|}
\hline \multirow[b]{2}{*}{ Characteristics } & \multicolumn{3}{|c|}{ Patients on WHO MDT (872) } \\
\hline & $\begin{array}{l}\text { \%Total } \\
\text { (872) }\end{array}$ & $\begin{array}{l}\text { Completed } \\
\text { treatment } \\
(621)\end{array}$ & $\begin{array}{l}\text { Defaulted } \\
\text { treatment } \\
(251)\end{array}$ \\
\hline \multicolumn{4}{|l|}{ Age (years) } \\
\hline$\leq 14$ & 12.5 & 13.8 & 9.2 \\
\hline $15-34$ & 37.8 & 36.9 & 40.2 \\
\hline $35-54$ & 35.6 & 36.4 & 33.5 \\
\hline$>54$ & 14.1 & 12.9 & 17.1 \\
\hline Mean (SEM) & $34.2(0.6)$ & $33.8(0.7)$ & $35.3(1.1)$ \\
\hline \multicolumn{4}{|l|}{ Sex } \\
\hline Male & 45.3 & 48.1 & 38.2 \\
\hline Female & 54.7 & 51.9 & 61.8 \\
\hline \multicolumn{4}{|c|}{$\begin{array}{l}\text { Delay in detection } \\
\text { (months) }\end{array}$} \\
\hline$\leq 12$ & 51.8 & 49.6 & 57.4 \\
\hline $13-36$ & 32.3 & 34.0 & 28.3 \\
\hline$>36$ & 15.8 & 16.4 & 14.3 \\
\hline \multicolumn{4}{|l|}{ Patches } \\
\hline $0-2$ & 79.1 & 78.1 & 81.7 \\
\hline $3-5$ & 20.9 & 21.9 & 18.3 \\
\hline \multicolumn{4}{|l|}{ Nerves } \\
\hline 0 & 59.7 & 58.3 & 63.3 \\
\hline 1 & 40.3 & 41.7 & 36.7 \\
\hline \multicolumn{4}{|l|}{ Clinical status } \\
\hline $\mathrm{I} / \mathrm{TT}$ & 12.9 & 12.7 & 13.5 \\
\hline BT/BTR & 84.6 & 85.0 & 83.7 \\
\hline $\mathrm{N}$ & 2.5 & 2.3 & 2.8 \\
\hline \multicolumn{4}{|l|}{ Smear } \\
\hline +ve & 0.2 & 0.3 & 0 \\
\hline$-V e$ & 18.4 & 18.8 & 17.1 \\
\hline Not done & 81.4 & 80.9 & 82.9 \\
\hline
\end{tabular}

persons ( $>54$ years). The incidence of relapse by sex, number of patches, presence of nerve and delay in treatment also did not vary (table 3 ).

Table 2 Clinical status of patients at the last visit who completed 6 months multidrug treatment (MDT) for leprosy

\begin{tabular}{lrrrrrr}
\hline & \multicolumn{7}{c}{ Duration of follow-up (years) } \\
\cline { 2 - 7 } Clinical status & $<1$ & $\mathbf{1 - 3}$ & $\mathbf{3 - 5}$ & $\mathbf{5 - 8}$ & $\mathbf{8}$ & Total (\%) \\
\hline Complete cure & 18 & 40 & 357 & 114 & 16 & $545(91.0)$ \\
Partial/not cure & 5 & 3 & 2 & 0 & 0 & $10(1.7)$ \\
Relapse & 1 & 11 & 12 & 2 & 0 & $26(4.3)$ \\
Relapse+reaction & 0 & 0 & 2 & 0 & 0 & $2(0.3)$ \\
Relapse+Grade 1 & 0 & 0 & 1 & 1 & 1 & $3(0.5)$ \\
Relapse+Grade 2 & 0 & 2 & 2 & 0 & 0 & $4(0.7)$ \\
Only Grade 1 & 0 & 0 & 1 & 0 & 0 & $1(0.2)$ \\
Only Grade 2 & 0 & 2 & 2 & 0 & 0 & $4(0.7)$ \\
Not & 0 & 0 & 1 & 0 & 0 & $1(0.2)$ \\
cured+Grade 1 & 1 & 2 & 0 & 0 & 0 & $3(0.5)$ \\
Type 1 reaction & 1 & 60 & 380 & 117 & 17 & $599(100.0)$ \\
Total \% & 25 & 4.2 & 10.0 & 63.4 & 19.5 & 2.9 \\
& \multicolumn{7}{c}{}
\end{tabular}

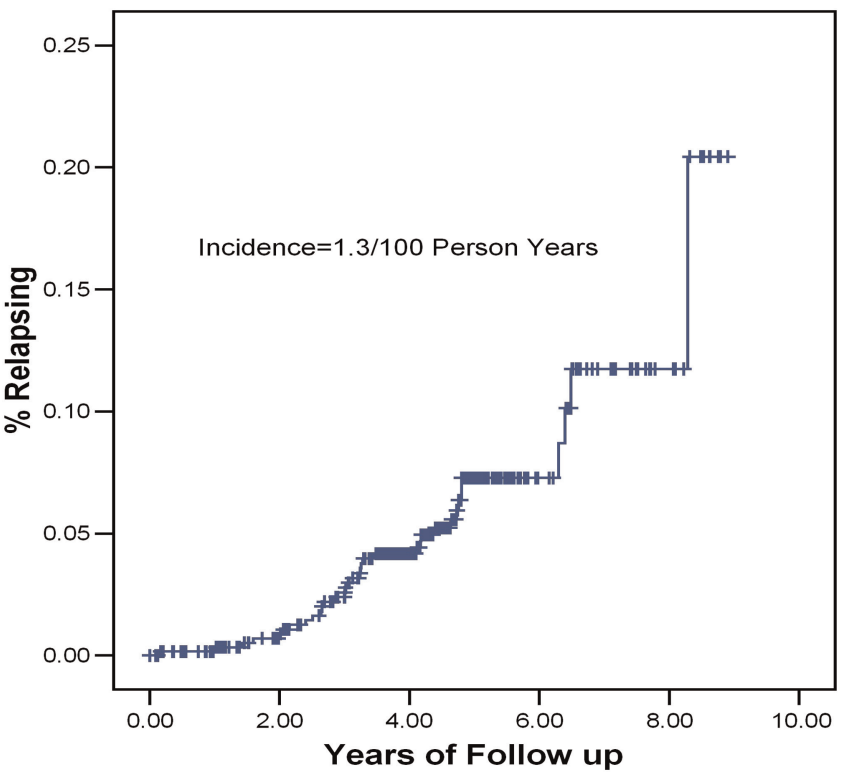

Figure 1 Incidence of relapse in paucibacillary leprosy after multidrug therapy.

Incidence of disability among completed treatment versus defaulters

The crude incidence of disability was observed to be $2.2 \%$ in comparison to $2.02 \%$ among defaulters. The crude incidence by age varied significantly among the completed treatment group $\left(\chi^{2}=22.7, p=0.0001\right)$ and no significant variation was found in defaulters. However, no

\begin{tabular}{|c|c|c|c|c|c|}
\hline & Cases & $\begin{array}{l}\text { Mean } \\
\text { PY }\end{array}$ & $\begin{array}{l}\text { PYAR } \\
\text { at risk }\end{array}$ & $\begin{array}{l}\text { No. of } \\
\text { relapses }\end{array}$ & $\begin{array}{l}\text { Relapse/ } \\
100 \\
\text { PYAR }\end{array}$ \\
\hline \multicolumn{6}{|c|}{ Age (years) } \\
\hline$<15$ & 81 & 4.62 & 374.4 & 06 & 1.6 \\
\hline $15-34$ & 221 & 4.23 & 933.8 & 11 & 1.2 \\
\hline $35-54$ & 220 & 4.53 & 996.7 & 10 & 1.0 \\
\hline$>54$ & 77 & 4.31 & 331.7 & 08 & 2.4 \\
\hline Total & 599 & 4.39 & 2636.4 & 35 & 1.3 \\
\hline \multicolumn{6}{|l|}{ Sex } \\
\hline Male & 287 & 4.27 & 1226.9 & 16 & 1.3 \\
\hline Female & 312 & 4.52 & 1409.5 & 19 & 1.4 \\
\hline \multicolumn{6}{|l|}{$\begin{array}{l}\text { Delay in } \\
\text { treatment } \\
\text { (years) }\end{array}$} \\
\hline Up to 1 & 301 & 4.37 & 1315.2 & 17 & 1.3 \\
\hline $1-2$ & 201 & 4.22 & 850.8 & 11 & 1.3 \\
\hline$>3$ & 97 & 4.85 & 470.4 & 07 & 1.5 \\
\hline \multicolumn{6}{|l|}{ Patches } \\
\hline $0-2$ & 466 & 4.37 & 2037.7 & 28 & 1.4 \\
\hline $3-5$ & 133 & 4.50 & 598.7 & 07 & 1.2 \\
\hline \multicolumn{6}{|l|}{ Nerves } \\
\hline 0 & 344 & 4.24 & 1458.7 & 21 & 1.4 \\
\hline 1 & 255 & 4.62 & 1177.7 & 14 & 1.2 \\
\hline
\end{tabular}


Table 4 Crude incidence of disability among PB leprosy

\begin{tabular}{|c|c|c|c|c|c|c|}
\hline \multirow[b]{2}{*}{ Factor } & \multicolumn{2}{|c|}{ Completed treatment } & \multicolumn{2}{|c|}{ Defaulters } & \multicolumn{2}{|l|}{$\chi^{2}$ and $p$ value } \\
\hline & Cases & $\%$ CID & Cases & $\%$ CID & Completed treatment & Defaulters \\
\hline Age (years) & & & & & $22.7,0.0001$ & \\
\hline$<15$ & 81 & 0 & 20 & 0 & & NS \\
\hline $15-34$ & 217 & 0.46 & 71 & 1.41 & & \\
\hline $35-54$ & 219 & 2.28 & 72 & 2.78 & & \\
\hline$>54$ & 75 & 9.33 & 35 & 2.86 & & \\
\hline Total & 592 & 2.20 & 198 & 2.02 & & \\
\hline Sex & & & & & NS & NS \\
\hline Male & 280 & 1.74 & 66 & 0 & & \\
\hline Female & 312 & 2.56 & 132 & 3.01 & & \\
\hline Patch & & & & & NS & NS \\
\hline $0-2$ & 459 & 2.18 & 164 & 1.83 & & \\
\hline $3-5$ & 133 & 2.26 & 34 & 2.94 & & \\
\hline Nerve & & & & & $4.1,0.043$ & NS \\
\hline 0 & 344 & 1.16 & 127 & 2.36 & & \\
\hline 1 & 248 & 3.63 & 71 & 1.41 & & \\
\hline \multicolumn{7}{|c|}{$\begin{array}{l}\text { Delay in treatment } \\
\text { (months) }\end{array}$} \\
\hline$<12$ & 299 & 1.67 & 115 & 2.61 & NS & NS \\
\hline $13-36$ & 200 & 3.00 & 55 & 0 & & \\
\hline$>36$ & 93 & 2.15 & 28 & 3.57 & & \\
\hline
\end{tabular}

significant difference in crude incidence of disability was observed by sex, number of patches and delay in treatment but by nerve status. Patient initially with no nerve developed disability more $\left(\chi^{2}=4.1, p=0.043\right)$ (table 4 ).

Of the 592 patients completed treatment and followed up for over 4 years (mean=4.4 years), 13 new cases of disability were observed during follow-up, suggesting incidence of disability as 0.50 per $100 \mathrm{PY}$ in comparison with 0.43 among defaulters (table 5, figure 2). Among the defaulters, incidence of disability was 0.43 in early default and 0.41 in late default.

\section{DISCUSSIONS AND CONCLUSION}

In the present study, $91 \%$ of the PB leprosy patients who completed treatment and were followed up were completely cured. The reaction rate was observed to be very low $(0.8 \%)$.

The occurrence of events like reaction, relapse and disability measures the effectiveness of any treatment regimen. In the present cohort of PB leprosy, the relapse rates have been reported in some studies after MDT with a low rate in programme-based data and high in closely monitored follow up studies. Some studies had reported a relapse rate of $<1 \%$ to $6.9 \%$ in $\mathrm{PB}$ leprosy. ${ }^{2-8} \mathrm{WHO}$ also reported a very low level of relapse ${ }^{17}$ but based on country reports. These reports have information not on all cases being given treatment but only those who report a relapse-resulting in very low reported relapses.

In the present study, the overall relapse rate is observed as 1.3/100 PY in the PB cohort observed during 20012010 in Agra District. Most relapses (30/35) were observed 1-5 years after releasing from treatment and almost $11.4 \%(4 / 35)$ beyond 5 years of follow-up. The relapse rates did not differ significantly by age, sex, delay at detection, clinical status and nerve involvement.

Although it is difficult to qualify for high and low relapse rates, relapses do occur and can occur anytime after release from treatment. ${ }^{13}$ More relapses may be seen if these patients are followed up for a further

Table 5 Incidence of disability/100 person-years at risk

\begin{tabular}{llllll}
\hline & Cases & Mean PY & $\begin{array}{l}\text { Person-years } \\
\text { at risk (PYAR) }\end{array}$ & $\begin{array}{l}\text { New disability } \\
\text { cases }\end{array}$ & $\begin{array}{l}\text { Incidence/100 } \\
\text { PYAR }\end{array}$ \\
\hline Completed MDT treatment & 592 & 4.40 & 2597.4 & 13 & $0.50^{*}$ \\
Defaulters of MDT & 198 & 4.72 & 933.7 & 4 & $0.43^{*}$ \\
Early (<3 months) & 142 & 4.87 & 691.4 & 3 & 0.43 \\
Late (3-5 month) & 56 & 4.33 & 242.3 & 1 & 0.41 \\
All & 789 & 4.48 & 3531.1 & 17 & 0.48 \\
\hline
\end{tabular}

MDT,multidrug therapy; PY, person-years; PYAR, person-years at risk.

${ }^{*}$ Log rank test $=0.23, p=0.63$. 


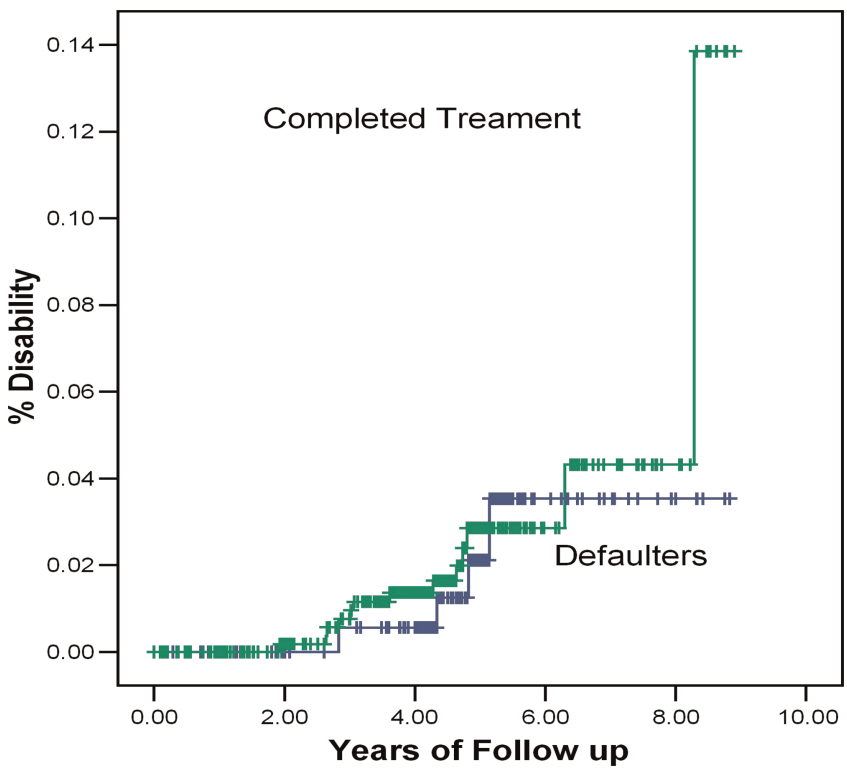

Figure 2 Incidence of disability in paucibacillary leprosy by treatment status.

longer period, but the extent is not easy to project. In many cases, the cause of relapse may be differential individuals' immunological response to mycobacteria. It would therefore be interesting to investigate the reason of relapses-is it insufficient treatment causing early relapse, persistent dormant mycobacteria leading to late relapse or immunological variations across populations giving a mix of the above two?

The incidence of disability was noticed in 13 patients (5 Grade 1 and 8 Grade 2). Although crude incidence of 2.02\% was noticed and significant variation by age $\left(\chi^{2}=22.7, \mathrm{p}=0.0001\right)$ and nerve involvement $\left(\chi^{2}=4.1\right.$, $\mathrm{p}=0.043)$, no significant difference was observed by sex, number of patches and duration of delay in treatment. The overall incidence of disability was 0.50 per $100 \mathrm{PY}$ among the group of completing treatment and 0.43 per 100 PY among treatment defaulters (table 5, figure 2) with very little difference between early and late defaulters $(\log$ rank test $=0.23, \mathrm{p}=0.63)$. This study observed much lower crude incidence of disability than as observed in a pre-MDT time study that reported crude incidence of Grade 1 and Grade 2 disabilities as $6.7 \%$ and $5.2 \%$, respectively. ${ }^{6}$

The findings of the present study once again confirms the findings of another cohort study on MB leprosy ${ }^{9}$ that treatment status (complete versus default) probably does not affect the risk of disability but initiation of treatment may do so. This is besides the fact regarding at what stage treatment is taken after the disease starts progressing. However, some early cases of Grade 1 disability may get altered to normal ${ }^{6}$ but many may advance disability to Grade 2. This is an important feature of leprosy and may be the result of already set-in pathways for disabilities. Therefore, more studies are required to understand and assess the cause of these pathways to disabilities.

Acknowledgements Authors gratefully acknowledge the help extended by the institute by providing internal grant for the study. Thanks are also due to all patients who cooperated in the study and the paramedical workers and district leprosy officer for the support.

Contributors Although all authors were responsible for the conception, design and acquisition of data, drafting, revising and final approval of the article, AK played the lead role in planning, conducting, supervising field study, analysis and report writing. AG carried out clinical evaluation and BKG was involved in clinical monitoring and report preparation.

Funding This study was supported by an institutional grant from the National JALMA Institute for Leprosy, Taj Ganj, Agra. No specific funding was asked from any external agency.

\section{Competing interests None.}

Patient consent Obtained.

Ethics approval Granted by the institutional ethical committee, which was being informed periodically about the progress of the work.

Provenance and peer review Not commissioned; externally peer reviewed.

Data sharing statement No additional data are available.

\section{REFERENCES}

1. Kaimal S, Thapa DM. Relapse in leprosy. Ind J Derm Ven Lep 2009;75:126-35.

2. Becx-Bleumink M. Relapse among leprosy patients treated with multidrug therapy. Experience in the leprosy control programme of ALERT in Ethiopia; practical difficulties with diagnosing relapse, operational procedures and criteria for diagnosing relapse. Int $J$ Lepr 1992;60:421-35.

3. The Leprosy Unit, WHO. Risk of relapse in leprosy. Indian J Lepr 1995;67:13-26.

4. Lobo D. Treatment failures with multidrug treatment. Lepr Rev 1992;63:93s-8s.

5. Abdul KS. An analysis of relapsed leprosy cases. Ind J Derm Ven Lep 2000;66:126-8.

6. Pandian TD, Sithambram M, Bharathi R, et al. A study of relapse in non-lepromatous and intermediate groups of leprosy. Ind $\mathrm{J}$ Lepr 1985;57:149-58.

7. Ali MK, Thorat DM, Subramanian M, et al. A study on trend of relapse in leprosy and factors influencing relapse. Indian $J$ Lepr 2005;77:105-15.

8. Boerrigter G, Ponnighaus JM, Fine PE, et al. Four-year follow up results of a WHO-recommended multiple-drug regimen in paucibacillary leprosy patients in Malawi. Int J Lepr 1991;59:255-61.

9. Kumar A, Girdhar A, Girdhar BK. Risk of developing disability in pre and post multidrug therapy treatment among multibacillary leprosy: Agra MB Cohort study. BMJ Open 2012;2:e000361. doi:10.1136/ bmlopen-2011-000361

10. Kumar A, Yadav VS, Girdhar A, et al. Some epidemiological observations on Leprosy in Agra, India. Int J Lepr 2001;69:234-40.

11. Kumar A, Girdhar A, Girdhar BK. Epidemiology of leprosy in Urban Agra, India. Lepr Rev 2003;74:31-4.

12. Kumar A, Girdhar A, Girdhar BK. Prevalence of leprosy in Agra district (U.P.) India during 2001-2003. Int J Lepr 2005;73:115-21.

13. Kumar A, Girdhar A, Chakma JC, et al. A rapid survey for leprosy in Agra District (2004-06): epidemiological observations. J Commun Dis 2008;40:277-84.

14. Ramachandran A, Seshadri PS. Relapses or reversal reaction: the case for a therapeutic trial of steroids. Lepr Rev 1988;59:271-272.

15. Statistical Program for Social Scientists (SPSS), version 12. USA, 1999

16. Le Chap T. Analysis of categorical data. USA: John Wiley \& Sons, 1988.

17. WHO Expert Committee on Leprosy. World Health Organization, Tech Rep Ser 1998;874:1-43. 